\title{
Sorbitol required for cell growth and ethanol production by Zymomonas mobilis under heat, ethanol, and osmotic stresses
}

\author{
Kaewta Sootsuwan ${ }^{1,2}$, Pornthap Thanonkeo ${ }^{2,3^{*}}$, Nawapote Keeratirakha ${ }^{2}$, Sudarat Thanonkeo ${ }^{4}$, Prasit Jaisil ${ }^{5}$ \\ and Mamoru Yamada ${ }^{6}$
}

\begin{abstract}
Background: During ethanol fermentation, the ethanologenic bacterium, Zymomonas mobilis may encounter several environmental stresses such as heat, ethanol and osmotic stresses due to high sugar concentration. Although supplementation of the compatible solute sorbitol into culture medium enhances cell growth of $Z$. mobilis under osmotic stress, the protective function of this compound on cell growth and ethanol production by this organism under other stresses such as heat and ethanol has not been described yet. The formation of sorbitol in Z. mobilis was carried out by the action of the glucose-fructose oxidoreductase (GFOR) enzyme which is regulated by the gfo gene. Therefore, the gfo gene in Z. mobilis was disrupted by the fusion-PCR-based construction technique in the present study, and the protective function of sorbitol on cell growth, protein synthesis and ethanol production by Z. mobilis under heat, ethanol, and osmotic stresses was investigated.
\end{abstract}

Results: Based on the fusion-PCR-based construction technique, the gfo gene in Z. mobilis was disrupted. Disruption of the $Z$. mobilis gfo gene resulted in the reduction of cell growth and ethanol production not only under osmotic stress but also under heat and ethanol stresses. Under these stress conditions, the transcription level of $p d c$, adhA, and $a d h B$ genes involved in the pyruvate-to-ethanol (PE) pathway as well as the synthesis of proteins particularly in Z. mobilis disruptant strain were decreased compared to those of the parent. These findings suggest that sorbitol plays a crucial role not only on cell growth and ethanol production but also on the protection of cellular proteins from stress responses.

Conclusion: We showed for the first time that supplementation of the compatible solute sorbitol not only promoted cell growth but also increased the ethanol fermentation capability of Z. mobilis under heat, ethanol, and osmotic stresses. Although the molecular mechanism involved in tolerance to stress conditions after sorbitol supplementation is still unclear, this research has provided useful information for the development of the effective ethanol fermentation process particularly under environmental conditions with high temperature or high ethanol and sugar concentration conditions.

Keywords: Zymomonas mobilis, Glucose-fructose oxidoreductase, Ethanol production, Heat stress, Ethanol stress, Osmotic stress, Fusion-PCR-based construction technique

\footnotetext{
* Correspondence: portha@kku.ac.th

2Department of Biotechnology, Faculty of Technology, Khon Kaen University, Khon Kaen 40002, Thailand

${ }^{3}$ Fermentation Research Center for Value Added Agricultural Products, Khon Kaen University, Khon Kaen 40002, Thailand

Full list of author information is available at the end of the article
} 


\section{Introduction}

Zymomonas mobilis, the Gram-negative facultative anaerobic bacterium, is unique in employing the Entner Doudoroff (ED) (2-keto-3-deoxy-6-phosphogluconate, KDPG), glyceraldehyde-3-phosphate-to-pyruvate (GP), and pyruvate-to-ethanol (PE) pathway for sugar catabolism and produces ethanol, and carbon dioxide as dominant fermentation products [1]. It generates one mole of ATP per mole of glucose utilized, which is a much lower level than that of the traditional ethanol-producing yeast, Saccharomyces cerevisiae. This bacterium thus appears to maintain a high level of glucose flux through these metabolic pathways to compensate its low ATP yield [2], for which large amounts of enzymes in the EDGP-PE pathway are expressed, constituting 30 to $50 \%$ of total soluble proteins of cells [1]. Z. mobilis has a relatively compact genome with a small number of genes (approximately 2,000 genes [3]). It possesses an incomplete Embden Meyerhof Parnas (EMP) pathway and an incomplete tricarboxylic acid cycle (TCA cycle) due to a lack of genes for 6-phosphofructokinase, 2-oxoglutarate dehydrogenase complex, and malate dehydrogenase [1-3], but possesses strong activities of the ED-GP pathway [4]. Comparative studies of both laboratory- and pilot-scales on kinetics of batch fermentation of $Z$. mobilis versus a variety of yeast have indicated the suitability of $Z$. mobilis over yeasts due to the following advantages: its higher sugar uptake rate and ethanol yield (97\% theoretical maximum yield), lower biomass production, and higher ethanol tolerance. Additionally, it does not require a controlled addition of oxygen during fermentation, it is amenable to genetic manipulation, and most importantly it is generally recognized as safe (GRAS) [1,5].

During fermentation, Z. mobilis produces not only ethanol and carbon dioxide but also an alcohol sugar, sorbitol, as a major by product when it is grown in sucrose or mixtures of glucose plus fructose medium [6-8]. Viikari [8] reported that the amount of sorbitol produced is equivalent to as much as $11 \%$ of the original carbon source. Only minor amounts of sorbitol are formed from glucose or fructose alone. The formation of sorbitol resulted from the in vivo inhibition of fructokinase by glucose. Subsequently, fructose is accumulated and then converted into sorbitol by the action of glucose-fructose oxidoreductase (GFOR), a periplasmic enzyme which comprises $1 \%$ of the total soluble protein in Z. mobilis $[7,9,10]$. Previous studies by Loos et al. [11] demonstrated that the addition of sorbitol into culture medium promotes the growth of $Z$. mobilis when grown in a high-sugar medium. This finding suggested that sorbitol protected cells from harmful effects caused by high osmotic pressures. However, during ethanol fermentation, $Z$. mobilis may encounter not only high osmotic stress but also heat and ethanol stresses [12,13], which adversely affect the ability of cells to perform efficient and consistent conversion of sugars to ethanol. Although the involvement of sorbitol in osmoprotection has been previously described [11], its protective function on cell growth and ethanol fermentation ability of $Z$. mobilis under heat and ethanol stresses has not been investigated yet. In the present study, we disrupted the gfo gene which encoded for GFOR in Z. mobilis and the disruptant strain was designated as $Z$. mobilis $\Delta g f o$. We showed for the first time that disruption of the gfo gene resulted in the reduction of cell growth and ethanol production in Z. mobilis under osmotic stress as well as under heat and ethanol stresses. We also demonstrated that the addition of sorbitol not only promoted cell growth but also increased the fermentation capability of $Z$. mobilis under all stress conditions tested. Sorbitol also protected cellular proteins from denaturation under stress conditions.

\section{Results}

\section{Disruption of the gfo gene in Z. mobilis}

For the disruption of the gfo gene, plasmid pZAUDGFOR containing the up- and down-region of the $g f o$ gene linked with kan cassette was transformed into $Z$. mobilis, and kanamycin-resistant transformants were selected. Among the kanamycin-resistant transformants obtained in this study, one isolate designated as Z. mobilis $\Delta g f o$ was chosen for disruption analysis of the $g f o$ gene. Disruption of the $g f o$ gene in Z. mobilis $\Delta g f o$ was confirmed by PCR using specific primers GFOR-int-5' and GFOR-int-3', as described in the Methods section. As shown in Figure 1, a PCR product of approximately $1.0 \mathrm{~kb}$ corresponding to the internal fragment of the $g f o$ gene was observed in the $Z$. mobilis parental strain, but not in the transformant. The nucleotide sequence of the PCR product from the parental strain showed a high degree of identity (99\%) with the gfo gene in the Z. mobilis, confirming that this amplified DNA fragment was a part of the $g f o$ gene in this microorganism (data not shown).

Disruption of the gfo gene in Z. mobilis was further confirmed by detection of sorbitol concentration in the Z. mobilis parental strain and transformant after cultivation in YP medium containing $300 \mathrm{~g} / \mathrm{L}$ sucrose as a carbon source. The results found that approximately

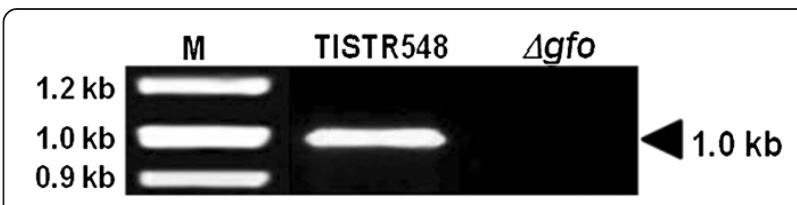

Figure 1 PCR analysis of the gfo gene in Z. mobilis parental (TISTR548) and disruptant ( $\Delta \boldsymbol{g} f \mathbf{f})$ strains. The size of the PCR product corresponding to an internal fragment of the gfo is indicated on the right. $M$, indicates the 100 bp DNA ladder. 
$3.84 \mathrm{~g} / \mathrm{L}$ of sorbitol was detected in the $Z$. mobilis parental strain. However, the level of sorbitol was not detectable in the transformant. Based on this result and PCR analysis, it was concluded that the gfo gene of $Z$. mobilis was disrupted in the transformant strain.

\section{Effect of stresses on growth of Z. mobilis parental and disruptant strains}

The effect of heat, ethanol, and osmotic stresses on the growth of $Z$. mobilis parental and disruptant strains were investigated and the results are illustrated in Figure 2. As shown in Figure 2A, growth of $Z$. mobilis TISTR548 and $Z$. mobilis $\Delta g f o$ was not significantly different when they were incubated at $30^{\circ} \mathrm{C}$. However, when temperatures were shifted from $30^{\circ} \mathrm{C}$ to $35^{\circ} \mathrm{C}$ and $37^{\circ} \mathrm{C}$, growth of $Z$. mobilis $\Delta g f o$ was remarkably decreased as compared to that of Z. mobilis TISTR548. At $39^{\circ} \mathrm{C}$, almost no growth of $Z$. mobilis $\Delta g f o$ was observed. The effect of ethanol stress on the growth of $Z$. mobilis is shown in Figure 2B. There were no significant differences in the growth of $Z$. mobilis TISTR548 and $Z$. mobilis $\Delta g f o$ when they were grown on YPG medium containing $0 \%(\mathrm{v} / \mathrm{v})$ ethanol. However, when ethanol concentration in the medium was increased up to $7 \%$ or $10 \%(\mathrm{v} / \mathrm{v})$, a pronounced decrease in growth of $Z$. mobilis $\Delta g f o$ was observed. In the YPG medium containing $13 \%(\mathrm{v} / \mathrm{v})$ ethanol, almost no growth of Z. mobilis $\Delta g f o$ was found. Figure $2 \mathrm{C}$ shows the effect of osmotic stress on cell growth of $Z$. mobilis TISTR548 and Z. mobilis $\Delta g f o$. Growth of Z. mobilis TISTR548 and Z. mobilis $\Delta g f o$ was not significantly different when they were grown on YP medium containing $200 \mathrm{~g} / \mathrm{L}$ sucrose.

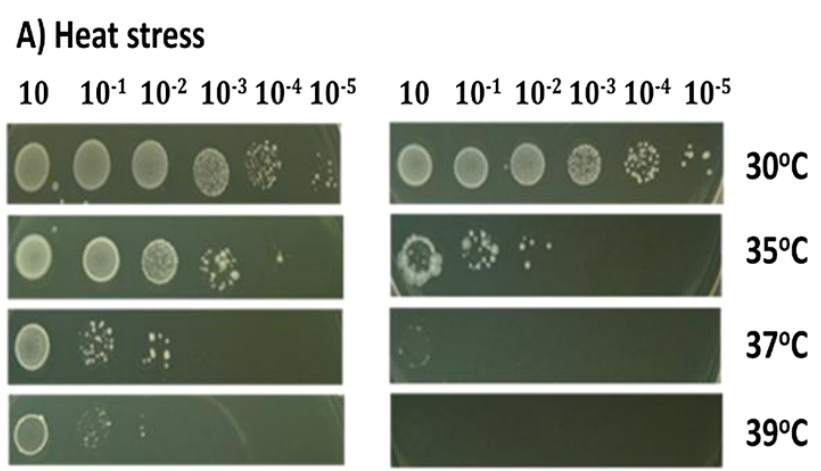

B) Ethanol stress

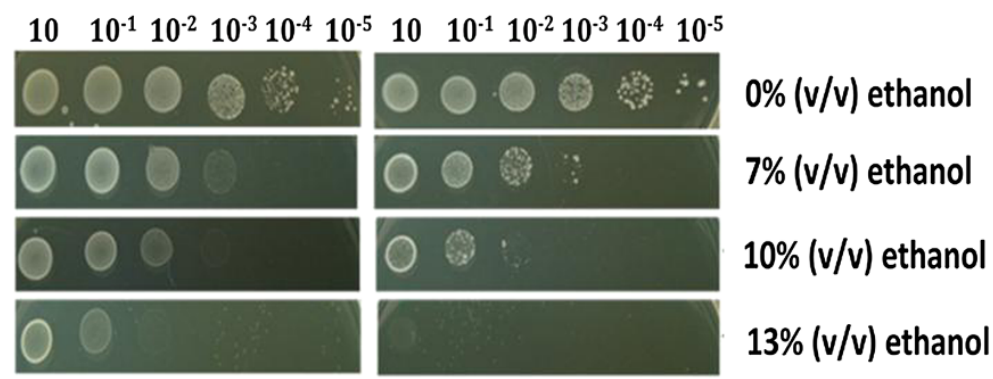

C) Osmotic stress

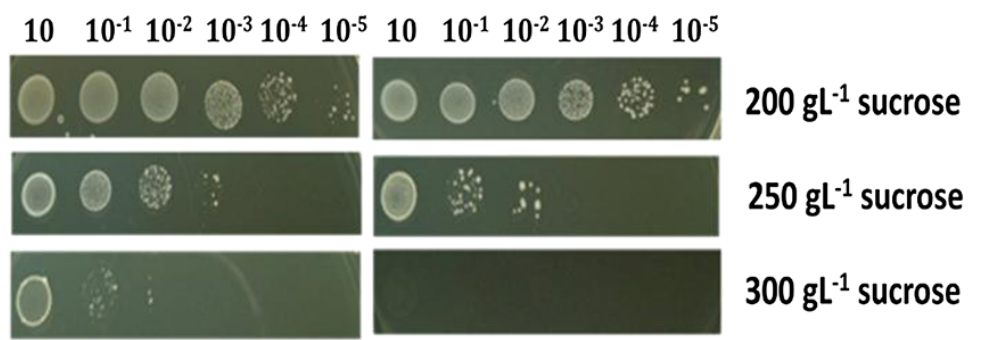

\section{Z. mobilis TISTR548 Z. mobilis $\Delta$ gfo}

Figure 2 Effect of heat, ethanol, and osmotic stresses on the growth of Z. mobilis TISTR548 and Z. mobilis $\Delta$ gfo. (A) Z. mobilis cells were grown in YP medium and incubated at $30,35,37$, and $39^{\circ} \mathrm{C}$ or (B) in YP medium containing 7,10 , and $13 \%$ (v/V) ethanol, (C) or in YP medium containing 200,250 and $300 \mathrm{~g} / \mathrm{L}$ sucrose. 
When the concentration of sucrose in the medium was increased, a drastically decreased growth of Z. mobilis $\Delta g f o$ was observed as compared to that of $Z$. mobilis TISTR548. Almost no growth of $Z$. mobilis $\Delta g f o$ was detected when it was cultured on YP medium containing $300 \mathrm{~g} / \mathrm{L}$ sucrose.

The effect of heat, ethanol, and osmotic stresses on the specific growth rate of $Z$. mobilis TISTR548 and $Z$. mobilis $\Delta g f o$ was also determined and the results are summarized in Table 1. The specific growth rates of $Z$. mobilis $\Delta g f o$ were lower than those of $Z$. mobilis TISTR548 under all stress conditions tested. When incubation temperatures, ethanol concentrations, or sucrose concentrations increased, the specific growth rates of both Z. mobilis TISTR548 and Z. mobilis $\Delta g f o$ were decreased. The lowest specific growth rates were found in $Z$. mobilis $\Delta g f o$ growing under the extreme stress conditions, (at $39^{\circ} \mathrm{C}$ or $13 \%(\mathrm{v} / \mathrm{v})$ ethanol or $300 \mathrm{gL}^{-1}$ sucrose, which were 1.89-, 2.84-, and 2.09-fold lower than those of $Z$. mobilis TISTR548 growing under the same conditions, respectively). These results are similar to those observed in Figure 2. It should be noted from these findings that $Z$. mobilis $\Delta g f o$ was highly sensitive to heat, ethanol, and osmotic stresses as compared to Z. mobilis TISTR548.

\section{Effect of stresses on ethanol production by Z. mobilis parental and disruptant strains}

The effect of heat stress on ethanol production by $Z$. mobilis TISTR548 and Z. mobilis $\Delta g f o$ was performed and the results are shown in Table 2. The ethanol concentration produced by $Z$. mobilis $\Delta g f o$ at $30^{\circ} \mathrm{C}$ was

Table 1 Specific growth rate of Z. mobilis TISTR548 and Z. mobilis $\Delta$ gfo under heat, ethanol, and osmotic stresses

\begin{tabular}{lcc}
\hline Stress conditions & \multicolumn{2}{c}{ Specific growth rate $\left(\mathbf{h}^{-1}\right)$} \\
\cline { 2 - 3 } & Z. mobilis TISTR548 & Z. mobilis $\boldsymbol{\Delta \text { gfo }}$ \\
\hline Heat stress & $0.574 \pm 0.27$ & $0.518 \pm 0.12$ \\
$30^{\circ} \mathrm{C}$ & $0.531 \pm 0.18$ & $0.310 \pm 0.04$ \\
$35^{\circ} \mathrm{C}$ & $0.287 \pm 0.26$ & $0.102 \pm 0.20$ \\
$37^{\circ} \mathrm{C}$ & $0.121 \pm 0.22$ & $0.064 \pm 0.12$ \\
$39^{\circ} \mathrm{C}$ & & \\
Ethanol stress & $0.587 \pm 0.24$ & $0.512 \pm 0.18$ \\
$0 \%(\mathrm{v} / \mathrm{v})$ ethanol & $0.417 \pm 0.17$ & $0.435 \pm 0.27$ \\
$7 \%(\mathrm{~V} / \mathrm{v})$ ethanol & $0.326 \pm 0.18$ & $0.290 \pm 0.15$ \\
$10 \%(\mathrm{v} / \mathrm{v})$ ethanol & $0.142 \pm 0.20$ & $0.050 \pm 0.16$ \\
$13 \%(\mathrm{v} / \mathrm{v})$ ethanol & & \\
Osmotic stress & & $0.502 \pm 0.03$ \\
$200 \mathrm{gL}^{-1}$ sucrose & $0.540 \pm 0.23$ & $0.349 \pm 0.10$ \\
$250 \mathrm{gL}^{-1}$ sucrose & $0.448 \pm 0.27$ & $0.057 \pm 0.18$ \\
$300 \mathrm{gL}^{-1}$ sucrose & $0.119 \pm 0.24$ & \\
\hline
\end{tabular}

$57.45 \pm 5.03 \mathrm{~g} / \mathrm{L}$, which was 1.27 -fold lower than that of the parental strain, Z. mobilis TISTR548. At $35^{\circ} \mathrm{C}$ and $37^{\circ} \mathrm{C}$, the ethanol concentrations produced by $Z$. mobilis $\Delta g f o$ were $21.00 \pm 0.63 \mathrm{~g} / \mathrm{L}$ and $17.96 \pm 0.42 \mathrm{~g} / \mathrm{L}$, respectively, which were 2.34- and 2.33-fold lower than those of $Z$. mobilis TISTR548. Although the ethanol yields from $Z$. mobilis TISTR548 and Z. mobilis $\Delta g f o$ were not much different, the volumetric ethanol productivities of $Z$. mobilis TISTR548 were about 1.51-, 2.28-, and 2.32-fold higher than those of $Z$. mobilis $\Delta g f o$ at $30^{\circ} \mathrm{C}, 35^{\circ} \mathrm{C}$, and $37^{\circ} \mathrm{C}$, respectively.

Table 2 also shows the effect of ethanol stress on ethanol production by $Z$. mobilis TISTR548 and $Z$. mobilis $\Delta g f o$. The ethanol concentration, volumetric ethanol productivity, and ethanol yield obtained from $Z$. mobilis $\Delta g f o$ grown in the medium containing 0 to $10 \%$ $(\mathrm{v} / \mathrm{v})$ ethanol were lower than those from Z. mobilis TISTR548. In the medium containing $10 \%(\mathrm{v} / \mathrm{v})$ ethanol, only $2.68 \pm 0.44 \mathrm{~g} / \mathrm{L}$ ethanol was produced by $Z$. mobilis $\Delta g f o$, which was 3.98 -fold lower than that of $Z$. mobilis TISTR548 growing in the same condition.

We also tested the effect of osmotic stress on ethanol production by Z. mobilis TISTR548 and Z. mobilis $\Delta g f o$ and the results are summarized in Table 2. Z. mobilis $\Delta g f o$ produced $54.12 \pm 5.22$ and $45.80 \pm 0.45 \mathrm{~g} / \mathrm{L}$ ethanol concentration when cultured in the medium containing 200 and $250 \mathrm{~g} / \mathrm{L}$ sucrose, which was 1.44- and 1.53-fold lower than that of $Z$. mobilis TISTR548 in the same condition, respectively. In addition, only $1.12 \pm 0.25 \mathrm{~g} / \mathrm{L}$ ethanol concentration was produced by $Z$. mobilis $\Delta g f o$ when cultured in the medium containing $300 \mathrm{~g} / \mathrm{L}$ sucrose, which was 30.73-fold lower than that of Z. mobilis TISTR548. These results clearly demonstrated that the fermentation activity of the $Z$. mobilis disruptant strain, Z. mobilis $\Delta g f o$, was highly sensitive to osmotic stress compared to that of the parental strain, Z. mobilis TISTR548, as observed under heat and ethanol stresses.

\section{Real-time RT-PCR analysis of pdc, adhA, and adhB genes under stress conditions}

The ethanol production capability of $Z$. mobilis disruptant strain as measured by ethanol content was lower than that of the parental strain under all stress conditions tested. This finding led us to the hypothesis that heat, ethanol, and osmotic stresses may suppress the expression of genes involved in the PE pathway. To test this hypothesis, we determined the expression levels of $p d c$, $a d h A$, and $a d h B$ genes in the disruptant strain by real-time RT-PCR using $16 \mathrm{~s}$ RNA as an internal control and compared its expression with those in the parental strain under all stress conditions. As shown in Figure 3, the mRNA expression levels of $p d c$, $a d h A$, and $a d h B$ of Z. mobilis TISTR548 under heat stress were 4.38-, 3.82-, and 3.81-fold higher than those of $Z$. mobilis $\Delta g f o$, 
Table 2 Effect of heat, ethanol and osmotic stresses on ethanol production by Z. mobilis TISTR548 and Z. mobilis $\Delta$ gfo

\begin{tabular}{|c|c|c|c|c|c|c|}
\hline \multirow{2}{*}{$\begin{array}{l}\text { Fermentation parameter } \\
\text { Heat stress }\end{array}$} & \multicolumn{3}{|c|}{ Z. mobilis TISTR548 } & \multicolumn{3}{|c|}{ Z. mobilis $\Delta g f o$} \\
\hline & $30^{\circ} \mathrm{C}$ & $35^{\circ} \mathrm{C}$ & $37^{\circ} \mathrm{C}$ & $30^{\circ} \mathrm{C}$ & $35^{\circ} \mathrm{C}$ & $37^{\circ} \mathrm{C}$ \\
\hline$P\left(g L^{-1}\right)$ & $72.69 \pm 10.62$ & $49.06 \pm 1.46$ & $41.87 \pm 4.93$ & $57.45 \pm 5.03$ & $21.00 \pm 0.63$ & $17.96 \pm 0.42$ \\
\hline$Q p\left(g^{-1} h^{-1}\right)$ & $1.21 \pm 0.18$ & $1.02 \pm 0.04$ & $1.16 \pm 0.14$ & $0.80 \pm 0.07$ & $0.44 \pm 0.01$ & $0.50 \pm 0.01$ \\
\hline Yps $\left(\mathrm{g} \mathrm{g}^{-1}\right)$ & $0.47 \pm 0.07$ & $0.46 \pm 0.08$ & $0.46 \pm 0.03$ & $0.47 \pm 0.06$ & $0.40 \pm 0.10$ & $0.44 \pm 0.09$ \\
\hline Time (hours) & 60 & 48 & 36 & 72 & 48 & 36 \\
\hline Ethanol stress & $0 \%$ & $7 \%$ & $10 \%$ & $0 \%$ & $7 \%$ & $10 \%$ \\
\hline$P\left(\mathrm{~g} \mathrm{~L}^{-1}\right)$ & $74.60 \pm 3.08$ & $40.73 \pm 2.68$ & $10.66 \pm 2.24$ & $58.03 \pm 5.16$ & $29.36 \pm 2.24$ & $2.68 \pm 0.44$ \\
\hline$Q p\left(g L^{-1} h^{-1}\right)$ & $1.55 \pm 0.20$ & $0.85 \pm 0.12$ & $0.22 \pm 0.10$ & $0.97 \pm 0.12$ & $0.61 \pm 0.04$ & $0.07 \pm 0.02$ \\
\hline Yps $\left(g g^{-1}\right)$ & $0.48 \pm 0.07$ & $0.44 \pm 0.10$ & $0.35 \pm 0.05$ & $0.47 \pm 0.08$ & $0.37 \pm 0.12$ & $0.10 \pm 0.03$ \\
\hline Time (hours) & 48 & 48 & 48 & 60 & 48 & 36 \\
\hline Osmotic stress & $200 \mathrm{~g} / \mathrm{L}$ & $250 \mathrm{~g} / \mathrm{L}$ & $300 \mathrm{~g} / \mathrm{L}$ & $200 \mathrm{~g} / \mathrm{L}$ & $250 \mathrm{~g} / \mathrm{L}$ & $300 \mathrm{~g} / \mathrm{L}$ \\
\hline$P\left(\mathrm{~g} \mathrm{~L}^{-1}\right)$ & $77.67 \pm 1.89$ & $69.85 \pm 2.44$ & $34.42 \pm 1.12$ & $54.12 \pm 5.22$ & $45.80 \pm 0.45$ & $1.12 \pm 0.25$ \\
\hline$Q p\left(g L^{-1} h^{-1}\right)$ & $1.29 \pm 0.03$ & $1.16 \pm 0.04$ & $0.57 \pm 0.14$ & $0.75 \pm 0.07$ & $0.64 \pm 0.02$ & $0.02 \pm 0.02$ \\
\hline Yps $\left(g g^{-1}\right)$ & $0.50 \pm 0.01$ & $0.51 \pm 0.01$ & $0.35 \pm 0.05$ & $0.46 \pm 0.11$ & $0.44 \pm 0.01$ & $0.07 \pm 0.03$ \\
\hline Time (hours) & 60 & 60 & 60 & 72 & 72 & 72 \\
\hline
\end{tabular}

$P$, ethanol concentration; $Q p$, volumetric ethanol productivity; $Y p s$, ethanol yield.

respectively. Under ethanol stress, the expression levels of $p d c, a d h A$, and $a d h B$ of $Z$. mobilis TISTR548 were 3.90-, 4.87- and 5.67-fold higher than those of Z. mobilis $\Delta g f o$, respectively. Likewise the expression levels of $p d c$, $a d h A$, and $a d h B$ of $Z$. mobilis TISTR548 under osmotic stress were 3.47-, 3.97-, and 5.63-fold higher than those of $Z$. mobilis $\Delta g f o$, respectively. These findings suggested that the expressions of $p d c, a d h A$, and $a d h B$ in the $Z$. mobilis parental strain were higher than those in the disruptant strain, which in turn lead to the high ethanol fermentation capability particularly under stress conditions. Due to the suppression of $p d c, a d h A$, and $a d h B$ genes by heat, ethanol, and osmotic stresses, the ethanol production by $Z$. mobilis $\Delta g f o$ was lower than that of the parental strain.

Protective function of sorbitol on cell growth and ethanol production by Z. mobilis parental and disruptant strains

To determine the protective function of sorbitol on cell growth and ethanol fermentation ability by $Z$. mobilis TISTR548 and Z. mobilis $\Delta g f o$ under stress conditions, cells were exposed to heat $\left(37^{\circ} \mathrm{C}\right)$, ethanol $(10 \%)$, or osmotic stress (300 g/L sucrose) in the presence of $50 \mathrm{mM}$ sorbitol. As shown in Table 3, supplementation of sorbitol into the culture medium enhanced cell growth (as specific growth rate) as well as the fermentation capability of Z. mobilis TISTR548 and Z. mobilis $\Delta g f o$ under all conditions tested. Under heat, ethanol, and osmotic stresses, the specific growth rates of sorbitol-supplemented cultures of Z. mobilis TISTR548 were 1.81-, 1.42-, and 4.30-fold higher than those of the control cultures without sorbitol supplementation. A pronounced increase in cell growth under sorbitol supplementation was found in the $Z$. mobilis disruptant strain. The sorbitol-supplemented cultures of $Z$. mobilis $\Delta g f o$ showed approximately 4.08-, 1.59-, and 6.19-fold higher in its specific growth rate than those of the control cultures without sorbitol supplementation under heat, ethanol, and osmotic stresses, respectively. With respect to the ethanol production, the maximum ethanol concentrations produced by sorbitol-supplemented cultures of Z. mobilis TISTR548 were 1.14-, 2.15-, and 2.14-fold higher than those of the control cultures without sorbitol supplementation under heat, ethanol, and osmotic stresses, respectively. In the case of $Z$. mobilis $\Delta g f o$, the maximum ethanol concentrations produced by

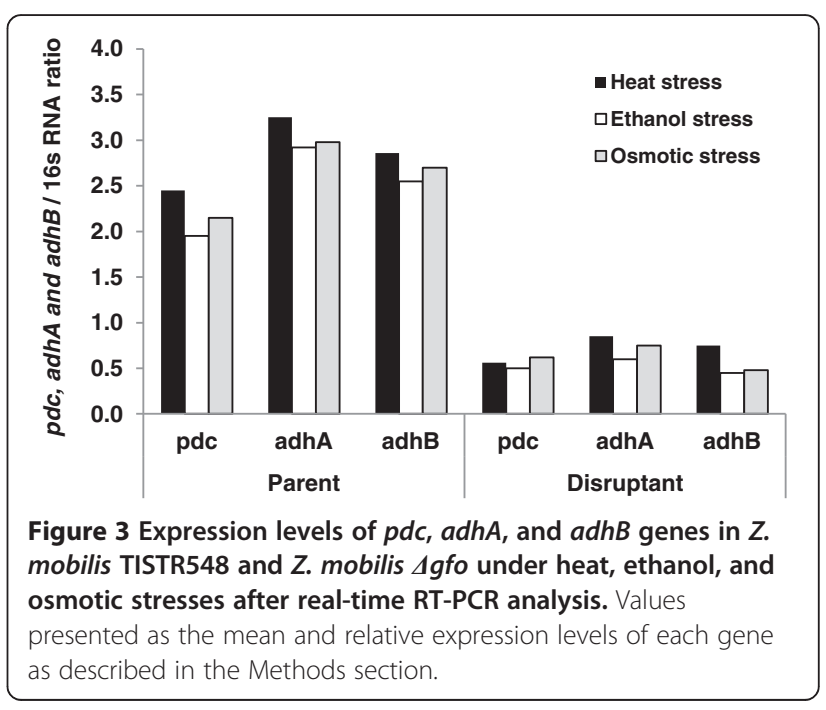


Table 3 Protective function of sorbitol on cell growth and ethanol production by Z. mobilis under heat, ethanol, and osmotic stresses

\begin{tabular}{|c|c|c|c|c|c|c|}
\hline \multirow[t]{3}{*}{ Treatment conditions } & \multicolumn{6}{|c|}{ Fermentation parameter } \\
\hline & \multicolumn{3}{|c|}{ Z. mobilis TISTR548 } & \multicolumn{3}{|c|}{ Z. mobilis $\Delta g f o$} \\
\hline & $\mu\left(\mathrm{h}^{-1}\right)$ & $P\left(\mathrm{~g} \mathrm{~L}^{-1}\right)$ & $Q_{P}\left(\mathrm{~g} \mathrm{~L}^{-1} \mathrm{~h}^{-1}\right)$ & $\mu\left(\mathrm{h}^{-1}\right)$ & $P\left(\mathrm{~g} \mathrm{~L}^{-1}\right)$ & $Q_{P}\left(\mathrm{~g} \mathrm{~L}^{-1} \mathrm{~h}^{-1}\right)$ \\
\hline \multicolumn{7}{|l|}{ Heat stress } \\
\hline $30^{\circ} \mathrm{C}$ & $0.566 \pm 0.32$ & $72.69 \pm 10.62$ & $1.21 \pm 0.18$ & $0.522 \pm 0.20$ & $57.45 \pm 5.03$ & $0.80 \pm 0.07$ \\
\hline $37^{\circ} \mathrm{C}$ & $0.280 \pm 0.24$ & $41.87 \pm 4.93$ & $1.16 \pm 0.14$ & $0.123 \pm 0.25$ & $17.96 \pm 0.42$ & $0.50 \pm 0.01$ \\
\hline $37^{\circ} \mathrm{C}+50 \mathrm{mM}$ sorbitol & $0.508 \pm 0.30$ & $47.70 \pm 3.56$ & $1.33 \pm 0.17$ & $0.502 \pm 0.22$ & $50.12 \pm 1.54$ & $1.04 \pm 0.06$ \\
\hline \multicolumn{7}{|l|}{ Ethanol stress } \\
\hline $10 \%(v / v)$ & $0.340 \pm 0.25$ & $12.10 \pm 3.20$ & $0.25 \pm 0.12$ & $0.286 \pm 0.18$ & $3.10 \pm 1.12$ & $0.06 \pm 0.01$ \\
\hline $10 \%(\mathrm{v} / \mathrm{v})+50 \mathrm{mM}$ sorbitol & $0.482 \pm 0.34$ & $26.02 \pm 2.15$ & $0.54 \pm 0.14$ & $0.456 \pm 0.26$ & $25.18 \pm 2.45$ & $0.52 \pm 0.04$ \\
\hline \multicolumn{7}{|l|}{ Osmotic stress } \\
\hline $300 \mathrm{~g} / \mathrm{L}$ sucrose & $0.126 \pm 0.32$ & $39.76 \pm 2.21$ & $0.66 \pm 0.04$ & $0.084 \pm 0.24$ & $1.62 \pm 0.01$ & $0.03 \pm 0.01$ \\
\hline $300 \mathrm{~g} / \mathrm{L}$ sucrose $+50 \mathrm{mM}$ sorbitol & $0.542 \pm 0.40$ & $84.98 \pm 1.31$ & $1.42 \pm 0.02$ & $0.520 \pm 0.32$ & $68.84 \pm 1.42$ & $1.15 \pm 0.02$ \\
\hline
\end{tabular}

$\mu$, specific growth rate $\left(\mathrm{h}^{-1}\right) ; P$, ethanol concentration produced $\left(\mathrm{g} \mathrm{L}^{-1}\right) ; Q_{p}$, volumetric ethanol productivity $\left(\mathrm{g} \mathrm{L}^{-1} \mathrm{~h}^{-1}\right)$.

sorbitol-supplemented cultures were 2.79-, 8.12-, and 42.49-fold higher than those of the control cultures without sorbitol supplementation under such stresses, respectively. These results clearly indicated that sorbitol reduced the sensitivity in growth and fermentation activity of cells to heat, ethanol and osmotic stresses.

\section{SDS-PAGE analysis}

The effect of heat, ethanol, and osmotic stresses on protein synthesis in Z. mobilis TISTR548 and Z. mobilis $\Delta g f o$ were analyzed by SDS-PAGE and the results are shown in Figure 4. Under stress conditions, the protein synthesis in Z. mobilis $\Delta g f o$ was almost suppressed as compared to that in Z. mobilis TISTR548 particularly under ethanol and osmotic stresses. Only a small number of proteins with the apparent molecular weight of approximately $58,54,48,45$, and $40 \mathrm{kDa}$ were visualized in the protein sample isolated from $Z$. mobilis $\Delta g f o$ growing under stress conditions. However, the synthesis of almost all proteins was recovered when sorbitol was supplemented into the culture medium. This can be seen from the protein patterns between sorbitolsupplemented and control cultures. In addition, the protein patterns from the sorbitol-supplemented cultures of $Z$. mobilis $\Delta g f o$ were almost similar to those of $Z$. mobilis TISTR548, except the sorbitol-supplemented cultures

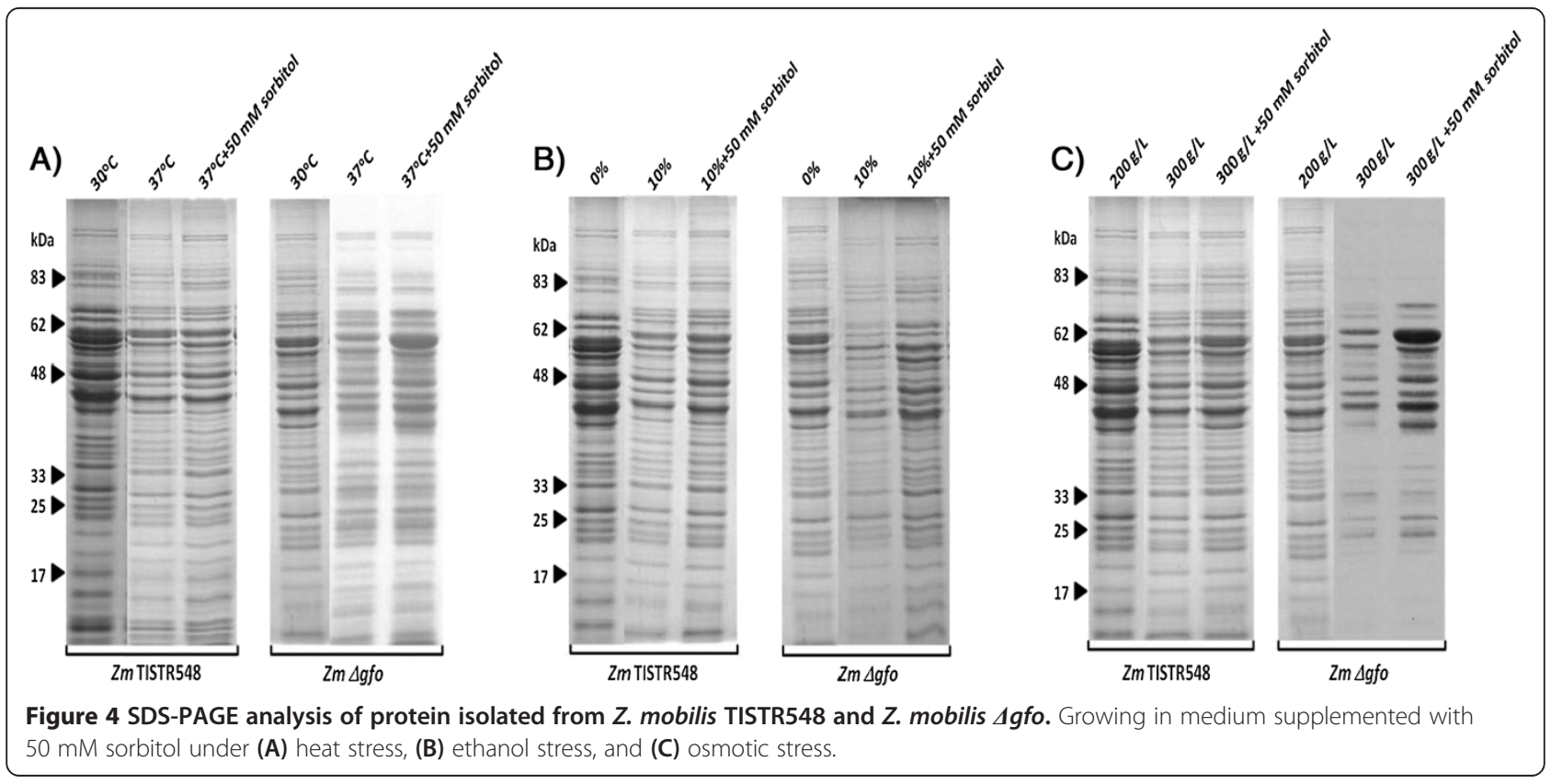


of Z. mobilis $\Delta g f o$ under osmotic stress. These results suggested that sorbitol may prevent protein from undergoing denaturation under heat, ethanol, and osmotic stresses.

\section{Complementation test of $Z$. mobilis disruptant strain}

To determine whether the growth defect of the $Z$. mobilis disruptant strain under stress conditions is due to the deletion of gfo gene, the recombinant plasmid carrying the full length open reading frame (ORF) of the gfo gene was introduced into the disruptant strain, as described in the Methods section. A PCR product of approximately $1.3 \mathrm{~kb}$ was observed in the selected complemented strain, suggesting the presence of the full length ORF of the gfo gene in this strain (data not shown). Specific growth rate of the complemented strain under stress conditions was analyzed and the results are summarized in Table 4. Introduction of the full length ORF of the gfo gene rescued the growth defect of the $Z$. mobilis disruptant strain under heat, ethanol, and osmotic stresses. The complemented strain produced approximately $3.52 \mathrm{~g} / \mathrm{L}$ of sorbitol when cultured in YP medium containing $300 \mathrm{~g} / \mathrm{L}$ sucrose. These findings suggested that the gfo gene is required for proper growth of $Z$. mobilis under heat, ethanol, and osmotic stresses.

\section{Discussion}

During ethanol fermentation, ethanologenic microorganisms like Z. mobilis or S. cerevisiae may encounter several environmental stresses such as heat [12,14], ethanol $[13,15]$, and osmotic stress at high sugar concentrations [11] and oxidative stress by endogenous reactive oxygen species (ROS) including hydrogen peroxide $\left(\mathrm{H}_{2} \mathrm{O}_{2}\right)$ [16] These stresses inhibit cell growth, cell division, cell viability $[17,18]$, and the fermentation activity of cells [19]. They can also modify plasma membrane fluidity [20] as well as disrupt cellular ionic homeostasis, leading to a reduction of metabolic activity and eventually cell death.
Therefore, defense mechanisms to overcome these stresses are important not only for the survival of these microorganisms but also for ethanol production. Synthesis of stress responsive proteins [12,21], fatty acids, particularly unsaturated fatty acids or saturated fatty acids, and ergosterol are a few of the mechanisms against heat and ethanol stresses which have been reported in Z. mobilis and S. cerevisiae [22]. In addition, formation of compatible solutes such as sorbitol in Z. mobilis [11] or trehalose in S. cerevisiae [23] to counteract the detrimental effects of osmotic stress, particularly under high sugar concentrations and ethanol stress, have also been reported.

Previous studies by Loos et al. [11] demonstrated that the addition of sorbitol into culture medium promoted cell growth of $Z$. mobilis in environments with high concentrations of sugar. However, to our knowledge, the protective function of sorbitol on cell growth and ethanol fermentation capability under heat and ethanol stresses in Z. mobilis has not been studied yet. The synthesis of GFOR protein is regulated by the gfo gene [24]. Therefore, the gene encoding GFOR ( $g f o$ ) in Z. mobilis was disrupted in this study and the protective effects of sorbitol on cell growth and ethanol production in the $Z$. mobilis parental and disruptant strains were determined. Based on the fusion PCR-based construction technique, the $g f o$ gene in Z. mobilis was disrupted, as confirmed by PCR analysis (Figure 1) and the determination of sorbitol content by HPLC in the parental and disruptant strains of $Z$. mobilis cells after cultivation in YP medium containing $300 \mathrm{~g} / \mathrm{L}$ sucrose. This fusion PCR-based construction technique has been wildly used to disrupt many genes, (for example cytochrome c peroxidase gene (cytC) in Z. mobilis [25]).

As shown in this study, disruption of the Z. mobilis gfo gene resulted in the reduction of cell growth both on solid and in liquid medium particularly under heat, ethanol, and osmotic stresses. The morphology of Z. mobilis parental and disruptant strains grown under

Table 4 Specific growth rate of $Z$. mobilis parental, disruptant and complemented strains under heat, ethanol, and osmotic stresses

\begin{tabular}{|c|c|c|c|c|c|}
\hline \multirow{2}{*}{$\begin{array}{l}\text { Stress } \\
\text { conditions }\end{array}$} & \multicolumn{5}{|c|}{ Specific growth rate $\left(\mathrm{h}^{-1}\right)$} \\
\hline & Parental & Parental (pZA22) & Disruptant & Disruptant (pZA22) & Complemented (pZA-GFORCOM) \\
\hline \multicolumn{6}{|l|}{ Heat stress } \\
\hline $30^{\circ} \mathrm{C}$ & $0.568 \pm 0.16$ & $0.550 \pm 0.17$ & $0.520 \pm 0.14$ & $0.510 \pm 0.13$ & $0.564 \pm 0.19$ \\
\hline $37^{\circ} \mathrm{C}$ & $0.283 \pm 0.12$ & $0.271 \pm 0.08$ & $0.111 \pm 0.04$ & $0.102 \pm 0.01$ & $0.276 \pm 0.11$ \\
\hline \multicolumn{6}{|l|}{ Ethanol stress } \\
\hline $0 \%(\mathrm{v} / \mathrm{v})$ & $0.572 \pm 0.18$ & $0.568 \pm 0.16$ & $0.521 \pm 0.18$ & $0.506 \pm 0.17$ & $0.562 \pm 0.17$ \\
\hline $10 \%(v / v)$ & $0.329 \pm 0.12$ & $0.326 \pm 0.11$ & $0.291 \pm 0.12$ & $0.288 \pm 0.11$ & $0.321 \pm 0.14$ \\
\hline \multicolumn{6}{|c|}{ Osmotic stress } \\
\hline $200 \mathrm{gL}^{-1}$ & $0.569 \pm 0.22$ & $0.562 \pm 0.23$ & $0.516 \pm 0.18$ & $0.511 \pm 0.16$ & $0.556 \pm 0.21$ \\
\hline $300 \mathrm{gL}^{-1}$ & $0.183 \pm 0.10$ & $0.177 \pm 0.10$ & $0.073 \pm 0.06$ & $0.075 \pm 0.07$ & $0.175 \pm 0.09$ \\
\hline
\end{tabular}


stress conditions was not different after the microscopic analysis, suggesting that the disruption of the gfo gene did not interfere with cell morphology in this organism (data not shown). As shown in Table 1, the specific growth rates of the $Z$. mobilis disruptant strain grown under stress conditions were less than those of the Z. mobilis parental strain. However, when sorbitol was supplemented into the culture medium, the specific growth rates of $Z$. mobilis parental and disruptant strains grown under heat, ethanol and osmotic stresses were increased as compared to the conditions without sorbitol supplementation. Complementation experiments by introducing the full length ORF of the $g f o$ gene into the $Z$. mobilis disruptant strain rescued the growth defect under heat, ethanol, and osmotic stresses (Table 4). These results clearly indicated that sorbitol is required for proper cell growth not only under osmotic stress as demonstrated by Loos et al. [11], but also under heat and ethanol stresses. We speculate from these findings that sorbitol may play a crucial role in cellular protection, by stabilizing the membrane bilayer or involving membrane fluidity, and by recovery of the cells from the stress.

Under stress conditions, the ethanol production capability of Z. mobilis parental and disruptant strains, as measured by ethanol concentration, volumetric ethanol productivity and ethanol yield, was decreased as compared to that under control conditions. Moreover, the ethanol fermentation ability of the $Z$. mobilis disruptant strain was also lower than that of the $Z$. mobilis parental strain (Table 2). This finding clearly demonstrated that heat, ethanol, and osmotic stresses caused inhibition of ethanol fermentation in Z. mobilis. One possible explanation that has been proposed for such detrimental effects is that heat, ethanol, and osmotic stresses cause a reduction in the effectiveness of the plasma membranes as a semipermeable barrier and transport process, allowing leakage of essential cofactors and coenzymes required for the activity of enzymes involved in glucose catabolism and alcohol production $[19,26]$. Surprisingly, the ethanol fermentation activity of $Z$. mobilis parental and disruptant strains was recovered when sorbitol was added into the fermentation medium (Table 3). This finding suggested that sorbitol not only enhanced cell growth but also increased the fermentation ability of this organism under stress conditions, since the expression levels of $p d c, a d h A$, and $a d h B$ genes involved in the PE pathway in the $Z$. mobilis disruptant strain was lower than that in the parental strain (Figure 3). Thus, reduction in the ethanol fermentation ability of the $Z$. mobilis disruptant strain might be due to the suppression of these genes by heat, ethanol, and osmotic stresses.

We have attempted to investigate the effect of heat, ethanol, and osmotic stresses on protein synthesis in
Z. mobilis parental and disruptant strains growing under stress conditions. As shown in Figure 4, the protein levels (as determined by protein intensity in the gel) of $Z$. mobilis disruptant strain growing under heat, ethanol, and osmotic stresses were lower than those of the Z. mobilis parental strain. One possibility is that heat, ethanol, and osmotic stresses suppress the synthesis of protein as well as cause protein denaturation [26]. These results are in agreement with those reported by Chandler et al. [27] and Hu et al. [28]. The synthesis of protein was increased when sorbitol was supplemented into the culture medium particularly proteins with the molecular weight of approximately 58, 54, 48, 45, and $40 \mathrm{kDa}$. We speculate from this finding that sorbitol plays a crucial role in the protection of proteins under heat, ethanol, and osmotic stresses. Yoo and Lee [29] reported that sorbitol can be used to preserve protein during storage since it can protect protein during dehydration by heat stress.

Based on these findings, we considered that sorbitol not only promoted cell growth but also increased the ethanol fermentation capability of $Z$. mobilis under heat, ethanol, and osmotic stresses. Increasing cell growth and ethanol fermentation activity in $Z$. mobilis might be related to the stabilization of cellular proteins by sorbitol. We are currently focused on the characterization of the genes and proteins responsible for sorbitol supplementation under stress conditions.

With respect to the substrate utilization, the narrow substrate spectrum with only three sugars, glucose, fructose, and sucrose, makes $Z$. mobilis not suitable for ethanol fermentation from sugar- and sugar-based feedstocks. On the other hand, ethanol yield from fructose and sucrose is very low since this microorganism accumulates sorbitol as a major byproduct. If $Z$. mobilis is engineered with pentose metabolic pathways, it might be suitable for ethanol production from lignocellulose biomass, since glucose is the only monomer sugar released from cellulose hydrolysis. The unique byproduct sorbitol might also provide some protection on cells from the toxicity of byproducts released during the pretreatment process of lignocellulose biomass. This hypothesis is now under our investigation.

\section{Conclusions}

$Z$. mobilis $\Delta g f o$ required the compatible solute, sorbitol, for normal cell growth, ethanol production as well as synthesis of cellular protein under stress conditions including heat, ethanol and osmotic stresses. This finding suggested that sorbitol plays an important role in the process of cell growth, ethanol fermentation, and protein synthesis not only under osmotic stress as previously reported but also under heat and ethanol stresses. Supplementation of sorbitol into the culture medium may be 
one of the effective approaches to improve the production yield of bioethanol or other chemicals under stress conditions with high temperature, high ethanol, or high sugar concentrations.

\section{Methods}

Strains, plasmid, and culture conditions

Z. mobilis TISTR548 was obtained from the Thailand Institute of Scientific and Technological Research (TISTR), Bangkok for use in this study. This strain exhibited higher growth and ethanol fermentation ability at relatively high temperature fermentation conditions $\left(37^{\circ} \mathrm{C}\right.$ and $40^{\circ} \mathrm{C}$ ) than those of the type strain, $Z$. mobilis ZM4 [30]. Both Z. mobilis TISTR548 and the gfo disruptant strain, Z. mobilis $\Delta g f o$, were grown in YPG medium ( $3 \mathrm{~g} / \mathrm{L}$ yeast extract, $5 \mathrm{~g} / \mathrm{L}$ peptone, $30 \mathrm{~g} / \mathrm{L}$ glucose) at $30^{\circ} \mathrm{C}$ [31]. When necessary, sugar stock solution autoclaved separately was added. Cultures were maintained on YPG medium solidified with $2 \%$ agar at $4^{\circ} \mathrm{C}$ with subculturing every 2 months. For the extraction of nucleic acids, Z. mobilis cells were grown in YPG medium at $30^{\circ} \mathrm{C}$ on a rotary shaker $(100 \mathrm{rpm})$. After 16 hours of incubation, cells were harvested by centrifugation at $5,000 \mathrm{rpm}$ for 5 minutes and washed twice with sterilized distilled water. Escherichia coli strain DH5 $\alpha$ was used for gene manipulation. It was grown in Luria-Bertani (LB) medium at $37^{\circ} \mathrm{C}$ on a rotary shaker (100 rpm). Shuttle vector pZA22, kindly provided by Professor Hideshi Yanase, was used to clone DNA fragments and to disrupt the Z. mobilis gfo gene in fusion PCR-based construction experiments. This vector contains the chloramphenicol $(\mathrm{cm})$ and tetracycline $(t c)$ resistant marker genes.

\section{DNA isolation and disruption of the $Z$. mobilis gfo gene}

The genomic DNA of $Z$. mobilis was prepared by the standard method [32]. The gfo gene in Z. mobilis was disrupted by the fusion PCR-based construction technique [33]. The procedures for gene disruption are illustrated in Figure 5 and the primers used in the gene disruption experiment are shown in Table 5. In the first step, the 5'- and 3'-flanking regions of the gfo gene were amplified by PCR using specific primers, GFOR-up-5, GFOR-up-kan-3, GFOR-down-kan-5, and GFOR-down3 , synthesized based on the gfo gene in Z. mobilis. The specific primers, GFOR-up-kan-3' and GFOR-down-kan5', directly adjacent to the marker cassette contain 5'-end (primer GFOR-up-kan-3') and 3'-end (primer GFORdown-kan-5') sequences of kan cassette at their 5'-ends. Two specific primers, kan-GFOR-5' and kan-GFOR-3, which sequences complementary to primer GFOR-upkan-3' and GFOR-down-kan-5' were used to amplify the kan cassette. In the second step, the 5'- and 3'-flanking regions of the $g f o$ gene were joined to the DNA fragment

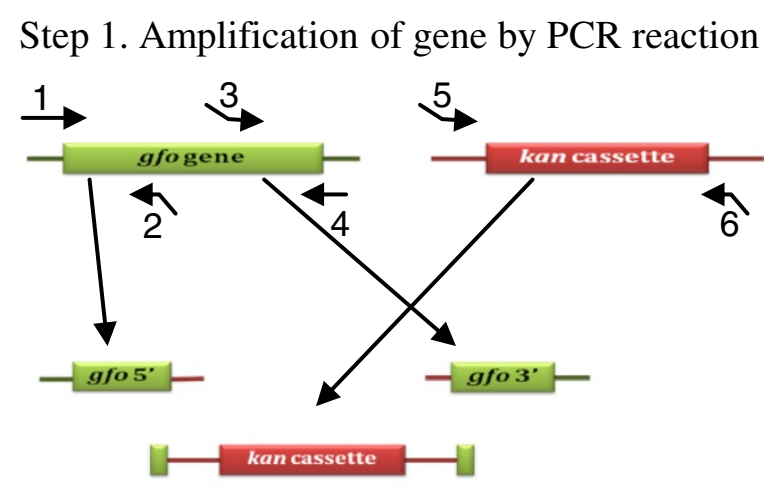

Step 2. Fusion PCR reaction

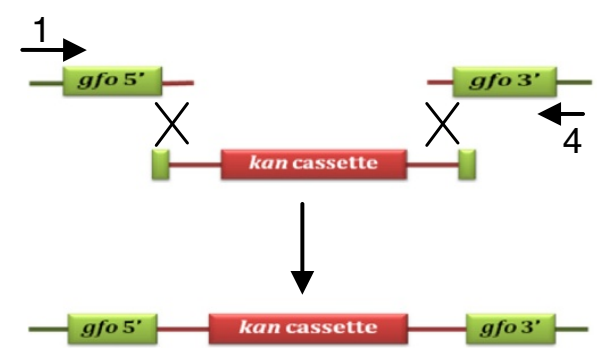

Figure $\mathbf{5}$ Schematic illustration of PCR-based construction of the gfo gene disruption.

of the kan cassette by PCR using the outermost primer GFOR-up-5' and GFOR-down-3', and the resulting DNA fragment of approximately $4.2 \mathrm{~kb}$ in length was cloned into pGEM-T Easy Vector (Promega, Medison, WI, USA) and then transformed into E. coli DH5 $\alpha$ by electroporation. All PCR reactions were performed by using a PCR amplification kit (Takara Biomedical, Otsu, Japan) according to the manufacturer's instructions. The positive clone was selected based on an ampicillin resistance marker. Plasmid DNA was isolated from this clone using the standard method [32] and then subjected to nucleotide sequencing using a DNA sequencing kit (Applied Biosystems, Foster City, CA, USA) with a MegaBACE 1000 automated DNA sequencer (Pharmacia Biotech, Uppsala, Sweden). After EcoRI digestion, a DNA fragment containing the up- and down-region of the $g f o$ gene linked with kan cassette was ligated into the EcoRI site of shutter vector pZA22 to generate plasmid pZAUDGFOR. This plasmid was then transformed into Z. mobilis by electroporation technique. After transformation, the transformants were screened based on the kanamycin resistance marker, and the $g f o$ gene in the selected transformants was confirmed by PCR using primers GFOR-int-5' and GFOR-int-3' synthesized based on an internal fragment of the gfo gene in Z. mobilis, with genomic DNA isolated from the parental strain and transformants as template. Nucleotide sequencing of the 
Table $\mathbf{5}$ List of primers used in the study

\begin{tabular}{|c|c|c|c|}
\hline Gene name & Primer name & Sequences $\left(5^{\prime}\right.$ to $\left.3^{\prime}\right)$ & Usage \\
\hline \multirow[t]{6}{*}{ gfo } & GFOR-up-5' & TGCCGCAGATAAACTCG & Gene disruption \\
\hline & GFOR-up-kan-3' & CAGCTCCAGCCTACACAGATTATCTGAAGACGAGA & \\
\hline & GFOR-down-kan-5' & AAGGAGGATATTCATATGTATGAAGCAGCTCGTACC & \\
\hline & GFOR-down-3' & CGCAAGAACCAATACCG & \\
\hline & GFOR-int-5' & AACGGATGACAACGCTT & \\
\hline & GFOR-int-3' & AGTCGTCGTGGTCGAAT & \\
\hline \multirow[t]{2}{*}{ kan } & kan-GFOR-5' & TCTCGTCTTGAGATAATCTGTGTAGGCTGGAGCTG & \\
\hline & kan-GFOR-3' & GGTACGAGCTGCTTCATACATATGAATATCCTCCTT & \\
\hline \multirow[t]{2}{*}{ adhA } & adhA-F & CATGAAAGCAGCCGTCA & Real-time PCR \\
\hline & $\operatorname{adhA}-\mathrm{R}$ & TACACCCGCGCAAGTGA & \\
\hline \multirow[t]{2}{*}{$a d h B$} & adhB-F & GTCAACGAAATGGGCGA & \\
\hline & adhB-R & GTGACGGTCAACAATGG & \\
\hline \multirow[t]{2}{*}{$p d c$} & pdc-F & GACTACAACCTCGTCCT & \\
\hline & pdc- $\mathrm{R}$ & CAGGGCATGGGAGCAAT & \\
\hline \multirow[t]{2}{*}{16 S RNA } & $16 s-F$ & CAGCACCTGTCTCTGATCCA & \\
\hline & $16 s-R$ & GTTCGGAATTACTGGGCGTA & \\
\hline \multirow[t]{2}{*}{$g f o^{a}$} & GFOR-com-5' & GCGAATTCATGACGAACAAAATCTCG & Complementation \\
\hline & GFOR-com-3' & GCGAATTCTCAATAACCACCCTGACG & \\
\hline
\end{tabular}

${ }^{a}$ The italic sequence corresponds to the EcoRI site.

PCR product was carried out as previously described to confirm the amplified product. Online database comparisons were performed with the BLAST algorithm in the GenBank and DNA DataBank of Japan (DDBJ) databases. To further confirm the disruption of the gfo gene, sorbitol production by $Z$. mobilis parental strain and disruptant was measured after growing both strains in YP medium containing $300 \mathrm{~g} / \mathrm{L}$ sucrose as a carbon source.

Effect of stresses on the growth of $Z$. mobilis parental and disruptant strains

The effect of stresses including heat, ethanol, and osmotic stresses on the growth of $Z$. mobilis parental and disruptant strains were tested. For heat stress, cells were grown on YP agar medium (3 g/L yeast extract, $5 \mathrm{~g} / \mathrm{L}$ peptone) containing $200 \mathrm{~g} / \mathrm{L}$ sucrose and incubated at $30,35,37$, and $39^{\circ} \mathrm{C}$ for 2 days. For ethanol stress, cells were grown on YP agar medium containing $200 \mathrm{~g} / \mathrm{L} \mathrm{su}-$ crose and ethanol at a final concentration of 7,10 , and $13 \%(\mathrm{v} / \mathrm{v})$, and then incubated at $30^{\circ} \mathrm{C}$ for 2 days. The effect of osmotic stress on cell growth was determined by culturing cells on YP agar medium containing 200, 250, and $300 \mathrm{~g} / \mathrm{L}$ sucrose for 2 days at $30^{\circ} \mathrm{C}$. After 2 days of cultivation, a part of culture was taken and serial dilutions of 10 times were made, and $10 \mu \mathrm{L}$ of each dilution was spotted on YP agar plate [34].

The effect of stresses on the specific growth rate of Z. mobilis parental and disruptant strains was also compared. For heat stress, cells were grown in YP liquid medium containing $200 \mathrm{~g} / \mathrm{L}$ sucrose and then incubated at $30,35,37$, and $39^{\circ} \mathrm{C}$. For ethanol stress, cells were grown in liquid YP medium containing $200 \mathrm{~g} / \mathrm{L}$ sucrose and ethanol at a final concentration of $0,7,10$, and $13 \%$ $(\mathrm{v} / \mathrm{v})$, and then incubated at $30^{\circ} \mathrm{C}$. For osmotic stress, cells were grown in liquid YP medium containing sucrose at a final concentration of 200, 250, and $300 \mathrm{~g} / \mathrm{L}$ and incubated at $30^{\circ} \mathrm{C}$. During cultivation, cells were harvested every 2 hours and spread onto YP agar plate. Cell growth was determined by colony-forming units (CFUs) and the specific growth rate of bacterial cells was calculated as described by Keeratirakha [35]. All experiments were performed in quadruplets and repeated twice. The data are means $( \pm S D)$ of the results of the experiments.

\section{Effect of stresses on ethanol fermentation by Z. mobilis parental and disruptant strains}

Batch ethanol fermentation by $Z$. mobilis parental and disruptant strains was carried out in $500 \mathrm{~mL}$ Erlenmeyer flasks equipped with an air-lock for an anaerobic growth condition as described by Taherzadeh et al. [36]. Next, $10 \%$ of active $Z$. mobilis cells were inoculated into $400 \mathrm{~mL}$ YP liquid medium containing sucrose as a sole carbon source and statically incubated at $30^{\circ} \mathrm{C}$. The influence of incubation temperatures on ethanol fermentation by $Z$. mobilis was performed by culturing cells in liquid YP medium containing $200 \mathrm{~g} / \mathrm{L}$ sucrose and incubated at various temperatures $\left(30,35\right.$, and $\left.37^{\circ} \mathrm{C}\right)$. The 
effect of ethanol stress on ethanol fermentation by $Z$. mobilis was determined by culturing cells in liquid YP medium containing $200 \mathrm{~g} / \mathrm{L}$ sucrose and ethanol at different concentrations $(0,7.0$, and $10 \%)$ and then incubated at $30^{\circ} \mathrm{C}$. Likewise, the effect of osmotic stress on ethanol production was evaluated by culturing cells in liquid YP medium containing different sucrose concentrations (200, 250, and $300 \mathrm{~g} / \mathrm{L}$ ) and incubated at $30^{\circ} \mathrm{C}$.

The protective effect of sorbitol against heat, ethanol, and osmotic stresses was tested. Briefly, the cultures growing in liquid YP medium containing $200 \mathrm{~g} / \mathrm{L}$ sucrose were exposed to heat $\left(37^{\circ} \mathrm{C}\right)$ and ethanol $(10 \%)$ stresses in the presence of $50 \mathrm{mM}$ sorbitol. For osmotic stress, cultures were grown in liquid YP medium containing $300 \mathrm{~g} / \mathrm{L}$ sucrose in the presence of $50 \mathrm{mM}$ sorbitol. During ethanol fermentation, samples were periodically withdrawn and analyzed for cell growth (as specific growth rate) and ethanol content. All the fermentation experiments were replicated twice and the average values $\pm \mathrm{SD}$ are presented in this study.

\section{RT-qPCR analysis of gene expression under stresses}

The expressions of alcohol dehydrogenase A ( $a d h A)$, alcohol dehydrogenase B ( $a h d B$ ), and pyruvate decarboxylase $(p d c)$ genes in Z. mobilis parental and disruptant strains were determined by real-time RT-PCR. Total RNA was isolated from Z. mobilis parental and disruptant strains grown in YP liquid medium under stress conditions, as described above, by using the GF-1 Total RNA Extraction Kit (Vivantis, Eco-Life Science, Kowloon, Hong Kong). The concentration of RNA was measured and adjusted by Nanodrop (Nanodrop Technologies, Wilmington, DE, USA). First-strand cDNA synthesis and SYBR Green RT-PCR assays were performed according to the manufacturer's instruction. The real-time RT-PCR amplifications were performed using the CFX96 Touch Real-Time PCR Detection System (Bio-Rad, Hercules, CA, USA). The reactions were carried out in a total volume of $25 \mu \mathrm{L}$ containing $12.5 \mu \mathrm{L}$ iQ SYBR Green Supermix, 0.5 $\mu \mathrm{L}$ diluted cDNA, $11.0 \mu \mathrm{L}$ sterile water, and $0.5 \mu \mathrm{L}$ of each forward and reverse primer. The thermal cycling conditions for PCR were initial denaturation at $95^{\circ} \mathrm{C}$ for 3 minutes, followed by 40 cycles each of denaturation at $95^{\circ} \mathrm{C}$ for 10 seconds, and annealing at $55^{\circ} \mathrm{C}$ for 30 seconds. The expression of $16 \mathrm{~s}$ RNA was analyzed as an internal control with specific primer as shown in Table 5. As a negative control, DEPCtreated water was used instead of cDNA template. All experiments were independently repeated at least twice in order to ensure reproducibility of the results.

Data from real-time RT-PCR amplifications were analyzed using CFX Manager Software (Bio-Rad, USA). The comparative $C t$ method was used to analyze the expression levels of $a d h A, a d h B$, and $p d c$ genes, based on the method described by Jiang et al. [37]. For data analysis, the relative expression levels were imported into Microsoft Excel (Redmond, WA, USA) for subsequent statistical analysis. All data are presented as the mean of relative mRNA expression.

\section{Protein extraction and SDS-PAGE}

Heat-, ethanol-, and osmotic-stressed cells were harvested by centrifugation, washed with sterilized distilled water, and suspended in a $10 \mathrm{mM}$ Tris $\mathrm{HCl}(\mathrm{pH} 7.0)$ buffer. Proteins were extracted from stressed cells by sonicating in Bioruptor (Cosmo Bio, Tokyo, Japan) for 10 minutes at $50 \%$ pulse duty cycle with the output power of 5 , as described by Thanonkeo et al. [12]. Protein concentration of the cell-free extracts was measured using Lowry reagent. For electrophoresis, approximately $20 \mu \mathrm{g}$ of the protein sample was heated at $100^{\circ} \mathrm{C}$ for 5 minutes and separated by SDS electrophoresis on $12 \%$ acrylamide gel with a constant voltage of $50 \mathrm{~V}$. After electrophoresis, proteins separated on the gel were visualized using Coomassie Brilliant Blue R250 and fixed in $10 \%$ ethanol.

\section{Complementation experiment}

The full length ORF of the $g f o$ gene was amplified by PCR with genomic DNA isolated from $Z$. mobilis parental strain as a template and specific primers, GFORcom-5' and GFOR-com-3' (Table 5), synthesized based on the 5'- and 3'-region of the gfo gene in this organism. All PCR reactions were performed by using a PCR amplification kit (Takara Biomedical) according to the manufacturer's instruction. The amplified product was purified and ligated into the EcoRI site of the shutter vector, pZA22. The resultant recombinant plasmid was designated as pZA-GFORCOM. This plasmid was then transformed into $Z$. mobilis disruptant strain by electroporation. After transformation, the complemented cells were screened based on the tetracycline resistance marker and confirmed by checking growth ability under stress conditions. The specific growth rate of the selected complemented strain grown in YP liquid medium under heat $\left(37^{\circ} \mathrm{C}\right)$, ethanol $(10 \% \mathrm{v} / \mathrm{v})$, and osmotic stress $(300 \mathrm{~g} / \mathrm{L}$ sucrose) was determined. The production of sorbitol in YP medium containing $300 \mathrm{~g} / \mathrm{L}$ sucrose by complemented strain was also examined. In addition, the replacement of the kan cassette by the full length ORF of the gfo gene after homologous recombination in the selected complemented strain was confirmed by PCR using specific primers GFOR-com-5' and GFORcom-3', as described above. The Z. mobilis parental and disruptant strains carrying pZA22 were generated as a control. 


\section{Analytical methods}

The fermentation broths were centrifuged at 13,000 rpm for 10 minutes to remove cells. The supernatant was then determined for total residual sugars by phenol sulfuric acid method [38]. Sorbitol concentration was analyzed by HPLC using an Aminex HPX $87 \mathrm{C}$ column $\left(300 \mathrm{~mm} \times 7.8 \mathrm{~mm}\right.$, temperature $\left.80^{\circ} \mathrm{C}\right)$ with a refraction index detector. The distilled deionized water was used as a mobile phase at a flow rate of $0.6 \mathrm{~mL} / \mathrm{min}$ and sorbitol was used as a standard. Ethanol concentration $(P, \mathrm{~g} / \mathrm{L})$ was analyzed by gas chromatography $(\mathrm{GC})(\mathrm{GC}-$ 14B, Shimadzu, Kyoto, Japan) using polyethylene glycol (PEG-20 M) packed column, nitrogen as a carrier gas, and a flame ionization detector (FID). Ethanol was quantified by using 2-propanol as an internal standard [39]. The ethanol yield $(Y p s)$ was calculated as the actual ethanol produced and expressed as gram ethanol per gram sugar utilized $(\mathrm{g} / \mathrm{g})$. The volumetric ethanol productivity $(Q p, \mathrm{~g} / \mathrm{L} . \mathrm{h})$ was calculated by the following equations: $Q p=P / t$; where $P$ is the ethanol concentration $(\mathrm{g} / \mathrm{L})$ and $t$ is the fermentation time (hours) giving the highest ethanol concentration.

\section{Abbreviations}

adhA: Alcohol dehydrogenase A; adhB: Alcohol dehydrogenase B; BLAST: Basic Local Alignment Search Tool; CFU: Conoly-forming unit; DDBJ: DNA DataBank of Japan; DEPC: Diethylpyrocarbonate; ED: EntnerDoudoroff; EMP: Embden-Meyerhof-Parnas; FID: Flame ionization detector; GC: Gas chromatography; GFOR: Glucose-fructose oxidoreductase; GP: Glyceraldehydes 3-phosphate-to-pyruvate; GRAS: Generally recognized as safe; HPLC: High performance liquid chromatography; KDPG: 2-keto3-deoxy-6-phosphogluconate; LB: Luria-Bertani; ORF: Open reading frame; PCR: Polymerase chain reaction; $p d c$ : Pyruvate decarboxylase; PE: Pyruvateto-ethanol; PEG: Polyethylene glycol; ROS: Reactive oxygen species;

RT: Reverse transcriptase; TCA: Tricarboxylic acid; TISTR: Thailand Institute of Scientific and Technological Research; YP: Yeast extract peptone; YPG: Yeast extract peptone glucose.

\section{Competing interests}

The authors declare that they have no competing interests.

\section{Authors' contributions}

KS carried out the disruption of the gfo gene in Z. mobilis. PT participated in the design of the study, carried out the expression analysis of genes and proteins and, complementation test, and wrote the manuscript. NK carried out the research experiments and data analysis. ST and PJ participated in the design of the study. MY participated in the design of the study and helped to draft the manuscript. All authors read and approved the final manuscript.

\section{Acknowledgements}

The authors thank $\mathrm{H}$ Yanase for providing the shuttle vector, pZA22. This research was carried out in collaboration with the Asian Core Program (ACP) between Yamaguchi University, Japan, and Khon Kaen University, Thailand, and was supported by the Scientific Cooperation Program agreed by the Japan Society for the Promotion of Science (JSPS) and the National Research Council of Thailand (NRCT). The authors would like to thank the Higher Education Research Promotion and National Research University Project of Thailand through Biofuels Research Cluster of Khon Kaen University, Office of the Higher Commission Education, and the Center for Alternative Energy Research and Development (AERD), Khon Kaen University, for financial support.

\section{Author details}

'Division of Biotechnology, Faculty of Agro-Industrial Technology, Rajamangala University of Technology Isan, Kalasin Campus, Kalasin 46000, Thailand. ${ }^{2}$ Department of Biotechnology, Faculty of Technology, Khon Kaen University, Khon Kaen 40002, Thailand. ${ }^{3}$ Fermentation Research Center for Value Added Agricultural Products, Khon Kaen University, Khon Kaen 40002, Thailand. ${ }^{4}$ Walai Rukhavej Botanical Research Institute, Mahasarakham University, Mahasarakham 44150, Thailand. ${ }^{5}$ Department of Plant Sciences and Agricultural Resources, Faculty of Agriculture, Khon Kaen University, Khon Kaen 40002, Thailand. ${ }^{6}$ Department of Biological Chemistry, Faculty of Agriculture, Yamaguchi University, Yamaguchi 753-8515, Japan.

Received: 27 April 2013 Accepted: 19 November 2013 Published: 5 December 2013

\section{References}

1. Sprenger GA: Carbohydrate metabolism in Zymomonas mobilis: a catabolic highway with some scenic routes. FEMS Microbiol Lett 1996, 145:301-307.

2. Barnell WO, Yi KC, Conway T: Sequence and genetic organization of a Zymomonas mobilis gene cluster that encodes several enzymes of glucose metabolism. J Bacteriol 1990, 172:7227-7240.

3. Seo JS, Chong H, Park HS, Yoon KO, Jung C, Kim JJ, Hong JH, Kim H, Kim JH, Kil JI, Park CJ, Oh HM, Lee JS, Jin SJ, Um HW, Lee HJ, Oh SJ, Kim JY, Kang HL, Lee SY, Lee KJ, Kang HS: The genome sequence of the ethanologenic bacterium Zymomonas mobilis ZM4. Nature Biotechnol 2005, 23:63-68.

4. Fuhrer T, Fischer E, Sauer U: Experimental identification and quantification of glucose metabolism in seven bacterial species. J Bacteriol 2005, 187:1581-1590.

5. Gunasekaran P, Chandra Raj K: Ethanol fermentation technology Zymomonas mobilis. Current Science (India) 1999, 77:56-68.

6. Barrow KD, Collins JG, Leigh DA, Rogers PL, Warr RG: Sorbitol production by Zymomonas mobilis. Appl Microbiol Biotechnol 1984, 20:225-233.

7. Leigh D, Scopes RK, Rogers PL: A proposed pathway for sorbitol production in Zymomonas mobilis. Appl Microbiol Biotechnol 1984, 20:413-415

8. Viikari L: Carbohydrate metabolism in Zymomonas mobilis. Crit Rev Biotechnol 1988, 7:237-261

9. Zachariou M, Scopes RK: Glucose-fructose oxidoreductase, a new enzyme isolated from Zymomonas mobilis that is responsible for sorbitol production. J Bacterio/ 1986, 167:863-869.

10. Loos H, Sahm H, Sprenger GA: Glucose-fructose oxidoreductase, a periplasmic enzyme of Zymomonas mobilis, is active in its precursor form. FEMS Microbiol Lett 1993, 107:293-298.

11. Loos H, Kramer R, Sahm H, Sprenger GA: Sorbitol promotes growth of Zymomonas mobilis in environmental with high concentrations of sugar: evidence for a physiological function of glucose-fructose oxidoreductase in osmoprotection. J Bacteriol 1994, 176:7688-7693.

12. Thanonkeo $\mathrm{P}$, Laopaiboon $\mathrm{P}$, Sootsuwan $\mathrm{K}$, Yamada M: Magnesium ions improve growth and ethanol production of Zymomonas mobilis under heat or ethanol stress. Biotechnol 2007, 6:112-119.

13. He MX, Wu B, Shui ZX, Hu QC, Wang WG, Tan XY, Tang XY, Zhu QL, Pan K, Li Q, Su XH: Transcriptome profiling of Zymomonas mobilis under ethanol stress. Biotechnol Biofuels 2012, 5:75-82.

14. Ghose TK, Bandyopadhyay KK: Studies on immobilized Saccharomyces cerevisiae. II. Effect of temperature distribution on continuous rapid ethanol formation in molasses fermentation. Biotechnol Bioeng 2004 24:797-804

15. Attfield PV: Stress tolerance: the key to effective strains of industrial baker's yeast. Nat Biotechnol 1997, 15:1351-1357.

16. Auesukaree C, Damnernsawad A, Kruatrachue M, Pokethitiyook P, Boonchird C, Kaneko Y, Harashima S: Genome-wide identification of genes involved in tolerance to various environmental stresses in Saccharomyces cerevisiae. J Appl Genet 2009, 50:301-310.

17. Michel GPF, Starka J: Effect of ethanol and heat stresses on the protein pattern of Zymomonas mobilis. J Bacteriol 1986, 165:1040-1042

18. Stanley GA, Hobley TJ, Pamment NB: Effect of acetaldehyde on Saccharomyces cerevisiae and Zymomonas mobilis subjected to environmental shocks. Biotechnol Bioeng 1997, 53:71-78.

19. Osman YA, Ingram LO: Mechanism of ethanol inhibition of fermentation in Zymomonas mobilis CP4. J Bacteriol 1985, 164:173-180. 
20. Moreau RA, Powell MJ, Fett WF, Whitaker BD: The effect of ethanol and oxygen on the growth of Zymomonas mobilis and the levels of hopanoids and other membrane lipids. Curr Microbiol 1997, 35:124-128.

21. Barbosa MFS, Yomano LP, Ingram LO: Cloning, sequencing and expression of stress genes from the ethanol-producing bacterium Zymomonas mobilis: the groESL operon. Gene 1994, 94:51-57.

22. Landolfo S, Zara G, Zara S, Budroni M, Ciani M, Mannazzu I: Oleic acid and ergosterol supplementation mitigates oxidative stress in wine strains of Saccharomyces cerevisiae. Int J Food Microbiol 2010, 141:229-235.

23. Lucero P, Peñalver E, Moreno E, Lagunas R: Internal trehalose protects endocytosis from inhibition by ethanol in Saccharomyces cerevisiae. Appl Environ Microbiol 2000, 66:4456-4461.

24. Kanagasundaram V, Scopes RK: Cloning, sequence analysis and expression of the structural gene encoding glucose-fructose oxidoreductase from Zymomonas mobilis. J Bacteriol 1992, 174:1439-1447.

25. Charoensuk K, Irie A, Lertwattanasakul N, Sootsuwan K, Thanonkeo P, Yamada M: Physiological importance of cytochrome $\mathrm{c}$ peroxidase in ethanologenic thermotolerant Zymomonas mobilis. J Mol Microbiol Biotechnol 2011, 20:70-82.

26. Hallsworth JE, Nomura Y, Iwahara M: Ethanol induced water stress and fungal growth. J Ferment Bioeng 1998, 86:451-456.

27. Chandler M, Stanley GA, Rogers P, Chambers P: A genomic approach to defining the ethanol stress response in the yeast Saccharomyces cerevisiae. Ann Microbiol 2004, 54:427-454.

28. Hu XH, Wang MH, Tan T, Li JR, Yang H, Leach L, Zhang RM, Luo ZW: Genetic dissection of ethanol tolerance in the budding yeast Saccharomyces cerevisiae. Genetics 2007, 175:1479-1487.

29. Yoo B, Lee CM: Thermoprotective effect of sorbitol on proteins during dehydration. J Agric Food Chem 1993, 41:190-192.

30. Thanonkeo P, Thanonkeo S, Charoensuk K, Yamada M: Ethanol production from Jerusalem artichoke (Helianthus tuberosus L.) by Zymomonas mobilis TISTR548. Afr J Biotechnol 2011, 10:10691-10697.

31. Michel GPF, Azoulay T, Starka J: Ethanol effect on the membrane protein pattern of Zymomonas mobilis. Ann Inst Pasteur Microbiol 1985, 136:173-179.

32. Sambrook J, Russell DW: Molecular Cloning: A Laboratory Manual. 3rd edition. Cold Spring Harbor, NY: Cold Spring Harbor Laboratory Press; 2001

33. Kuwayama H, Obara S, Morio T, Katoh M, Urashihara H, Tanaka Y: PCRmediated generation of a gene disruption construct without the use of DNA ligase and plasmid vectors. Nucleic Acids Res 2002, 30:1-5.

34. Ying Z, Ma R, Zhao Z, Zhou Z, Lu W, Chen M: irrE, an exogenous gene from Deinococcus radiodurans, improves the growth of and ethanol production by a Zymomonas mobilis strain under ethanol and acid stresses. J Microbiol Biotechnol 2010, 20:1156-1162.

35. Keeratirakha N: A Comparative Study on Ethanol Production Ability between Zymomonas mobilis TISTR548 and Z. mobilis $\triangle g f o$, Master thesis. Khon Kaen: Khon Kaen University, Biotechnology Department; 2011.

36. Taherzadeh MJ, Eklund R, Gustafsson L, Niklasson C, Liden G: Characterization and fermentation of dilute-acid hydrolyzates from wood. Ind Eng Chem Res 1997, 36:4659-4665.

37. Jiang H, Ren F, Sun J, He L, Li W, Xie Y, Wang Q: Molecular cloning and gene expression analysis of the leptin receptor in the Chinese mitten crab Eriocheir sinensis. Plos One 2010, 5:1-9.

38. Scherz J, Bonn G: Analytical Chemistry of Carbohydrates. New York, NY: Georg Thieme Verlag; 1998.

39. Laopaiboon L, Nuanpeng S, Srinophakun P, Klanrit P, Laopaiboon P: Ethanol production from sweet sorghum juice using very high gravity technology: effects of carbon and nitrogen supplementations. Bioresour Technol 2009, 100:4167-4182.

doi:10.1186/1754-6834-6-180

Cite this article as: Sootsuwan et al: Sorbitol required for cell growth and ethanol production by Zymomonas mobilis under heat, ethanol, and osmotic stresses. Biotechnology for Biofuels 2013 6:180.

\section{Submit your next manuscript to BioMed Central and take full advantage of:}

- Convenient online submission

- Thorough peer review

- No space constraints or color figure charges

- Immediate publication on acceptance

- Inclusion in PubMed, CAS, Scopus and Google Scholar

- Research which is freely available for redistribution

Submit your manuscript at www.biomedcentral.com/submit
Ciomed Central 